\title{
A emergência da escola
}

\section{The emergency of the school}

\author{
Arthur Cassio de Oliveira Vieira. \\ Doutorando do Programa de Pós-Graduação em Educação da Universidade Federal \\ do Rio Grande do Norte, arthur_cassio@yahoo.com.br
}

Resenha: GONDRA, José G. (2018). A emergência da escola. São Paulo, SP: Cortez.

José Gonçalves Gondra é professor titular da Universidade Estadual do Rio de Janeiro (UERJ), com Mestrado e Doutorado em Educação. Pesquisador na área de História da Educação, escreveu "A emergência da escola" como resultado de uma pesquisa realizada no âmbito do Núcleo de Ensino e Pesquisa em História da Educação da Universidade do Estado do Rio de Janeiro (NEPHE/UERJ), integrado pelos pesquisadores Marina Natsume Uekane, Giselle Baptista Teixeira, Daniel Cavalcanti de Albuquerque Lemos, Pedro Paulo Hausmann Tavares, Pollyanna Gomes Pinho, Inára Garcia e Angélica Borges, citados como coautores do texto.

O livro é dividido em 5 capítulos. O primeiro deles é intitulado "O governo das multidões"; o segundo, "A instrução reformada"; o terceiro trata do "Governo dos professores"; o quarto do "Governo das aulas"; e, por fim, o quinto capítulo que tem como título "Um governo para si". Cabe ainda destacar a transcrição literal de documentos em anexo, podendo servir para futuras pesquisas na área de História da Educação. Trata-se do Regulamento da Província do Espírito Santo (1848), o Regulamento da Província do Rio de Janeiro (1849), o Regulamento da Corte (1854), Cartas do professor da roça (1864) e Manifesto dos Professores Públicos da Instrução Primária da Corte (1871).

Com comentários de António Nóvoa, Margareth Rago e apresentação de Diana Vidal, o livro publicado em 2018 pela Cortez Editora traz a luz uma reflexão sobre o surgimento e organização da escola a partir das iniciativas governamentais no Brasil Imperial e suas consequências, enfatizando, sobretudo, a Reforma de 1854, que criou a Inspetoria Geral da Instrução Primária e Secundária da Corte (IGIPSC). O autor a toma como um marco, pois é a partir dela que se criam regras para profissionalização da instrução, acesso e permanência de professores e alunos, bem como a fiscalização do sistema educacional. Temos, de tal modo, a partir desta Reforma a instalação de uma efetiva máquina de governo com relação a educação.

O autor trabalha com o conjunto de três reformas implementadas durante a gestão do Ministro Luiz Pedreira do Coutto Ferraz. São elas: o Regulamento da Província do Espírito Santo (1848), o Regulamento da Província do Rio de Janeiro (1849) e o Regulamento da Corte (1854). Segundo a análise de Gondra, elas 
possuem o objetivo principal de inserir o Brasil no mundo moderno, a partir da intervenção realizada na educação. Para tanto, era de primeira importância empreender mudanças na escola, determinando desde a organização administrativa, a idade dos alunos, os conteúdos a serem ensinados, a estrutura física das instituições, os métodos de ensino e a formação dos professores. Destaca-se também a discriminação daqueles que poderiam ter acesso ao ambiente escolar, excluindo-se escravos e portadores de moléstias contagiosas, o que evidencia a visão higienista do período.

Gondra também problematiza a hierarquização social promovida pela divisão sexual do alunado, bem como pela distinção qualitativa entre as escolas das vilas e dos pequenos povoados. Os professores precisavam, a partir das reformas de Coutto Ferraz, demonstrar domínio dos saberes e boa conduta social. O controle e a regulação impunham-se tanto às instituições de ensino públicas quanto às privadas. Era impositiva também a ideia de educação como obrigatoriedade, a fim de construir novos cidadãos e valores por meio de uma escola pensada de maneira racional e profissionalizada.

Já no primeiro capítulo, partindo de uma análise foucaultiana do exercício do poder, Gondra nos instiga a perceber a escola como um meio de governar o corpo social, através da disciplinarização dos alunos e homogeneização dos saberes e dos docentes. De maneira que o autor apresenta o tema do estudo realizado, dando ênfase a sua hipótese de que a escola foi utilizada no Brasil e em outros lugares do mundo como uma máquina civilizatória, a fim de atender aos interesses do Estado.

Nota-se em suas discussões, a percepção de que momentos de mudanças políticas e sociais são propícios para a implementação de reformas, que se justificam pela ineficácia do sistema educacional. Surge então, na visão do autor, o que ele classifica como cultura da reforma, propiciando a revisão de estratégias e imposição de novas regras que possibilitem bem governar as multidões. Trata-se, portanto, de "acontecimentalizar" a reforma, indo além da pura decodificação de leis. Busca-se observar as suas causas e efeitos, que orientam práticas e vivências no cotidiano escolar.

Um desses aspectos se refere à formação de professores. $O$ autor trata do sistema de professores adjuntos, a partir do qual os futuros docentes aprendiam o ofício através da observação e da prática. Esse modo "artesanal" de formação sofre fortes críticas ao observar-se a sua fragilidade frente ao modelo escolarizado proposto pela Escola Normal. O livro apresenta a transcrição de textos publicados nos periódicos da época, como "A Instrucção Pública" e "A verdadeira Instrucção Pública”, em que são criticadas a má formação e a baixa remuneração dos professores primários.

Nesse contexto de insuficiência e ineficácia, o autor aborda a criação da primeira Escola Normal para formação dos professores primários, em 25 de março de 1874, no Rio de Janeiro. A normalização dos professores atendia a uma demanda de padronização e profissionalização do ensino, rompendo com a "formação artesanal" e difundindo novas ideias pedagógicas e metodológicas. Porém, a mesma não surtiu inicialmente os efeitos esperados.

Anos depois, com a criação de uma Escola Normal Pública da Corte, em 1880, passa a vigorar um novo regulamento que determina a oferta de outras disciplinas como Fisiologia e Higiene, Ciências Físicas e Naturais, Filosofia e Princípios de Direito Público e Natural. Gondra infere que a partir deste momento, se 
dá um rompimento com o mero letramento e evidencia-se a articulação do projeto governamental para a sociedade com a formação e o currículo.

O processo seletivo para admissão dos docentes também é descrito por Gondra, que ao destacar as etapas de prova escrita e entrevista, prova de conhecimentos prévios e idoneidade moral, reflete sobre o estabelecimento de um perfil desejável para os professores, de acordo com o Regulamento de 1854. Isto fazia, segundo o autor, com que os postulantes a cadeira de professor produzissem uma representação de si mesmos, apoiada em certificados e atestados de moralidade.

Neste sentido, o livro traz tabelas em que detalha o rigoroso processo de apresentação dos certificados de moralidade e maioridade, com exemplares textuais dos mesmos. Apresenta também, modelos de justificativa para quem buscava a isenção dessa massa burocrática. $O$ diálogo com Foucault se explicita nesse âmbito, apresentando as linhas de fuga ao que era estabelecido legalmente, em que se inscrevem relações de força e poder, jogos de interesses entre sujeitos e instituições socialmente legitimadas.

Acerca deste aspecto, Gondra apresenta as críticas do professor Manoel José Pereira Frazão, que em suas "Cartas do professor da roça" denuncia as práticas de burla nos concursos. Outra crítica presente no livro é à ideia de docência como missão, ao que se contrapõe a busca pela profissionalização e valorização. O livro apresenta as estratégias governamentais para tal valorização e formação continuada, mas também as inciativas dos próprios professores. Destaca-se a realização de conferências pedagógicas por parte do governo (destinadas aos docentes), por meio das quais se buscava difundir os valores da ciência, do progresso e da modernidade, e conferências populares ou literárias conduzidas pelos docentes e destinadas a todo corpo social.

As conferências pedagógicas eram reuniões promovidas pelo Estado Imperial para discutir questões pertinentes a instrução, de participação obrigatória para os professores de instituições públicas e facultativa para os de escolas particulares. Eram previstas desde o Regulamento de 1854, mas só em 1872, durante a gestão do Inspetor Geral José Bento da Cunha Figueiredo, é que estas serão organizadas. Gondra as compreende como uma estratégia para o exercício do poder e controle sobre a profissão docente, promovendo a homogeneização e estabelecendo um código profissional partilhado entre todos. A discussão foucaultiana acerca do exercício do poder também aparece no tocante a estas conferências, em que a própria conformação espacial e distribuição dos sujeitos nas reuniões buscava delimitar diferentes estratos de poder e legitimidade.

Para além disto, refere-se também aos mecanismos de controle da participação dos docentes e punição dos faltosos. De tal modo, nota-se o governo daqueles que ajudariam o Estado a governar em busca de seus objetivos. Porém, apesar destas flagrantes tentativas de padronização e coerção dos professores, a análise de Gondra abre espaço para o anômalo. O autor apresenta casos de protesto ou mesmo de boicote às conferências por parte dos docentes. Nota-se, portanto, que a profissionalização no período imperial não esteve subordinada unicamente às ações governamentais, mas também à capacidade de organização e ação dos professores.

Assim como a tentativa de governar os professores, o autor apresenta o momento da aula também como propício para efetivar uma direção e um controle sobre "pequenas multidões". Neste capítulo, Gondra toma como fontes principais os 
livros didáticos, partindo da hipótese de que estes funcionavam como instrumentos para efetivação do projeto educacional, veiculando os saberes e valores desejáveis para a produção de sujeitos governáveis e submetidos a um conjunto de regras.

O governo incentivava a produção de livros e compêndios, inclusive através de premiação garantida aos autores, dos quais somente aqueles autorizados pelo Conselho de Instrução Pública eram admitidos nas escolas públicas e privadas. Entretanto, o conjunto documental apresentado pelo autor, dá conta de que, por vezes, o Estado não cumpria com a sua parte no trato da remuneração dos premiados.

A produção de livros didáticos aparece em Gondra também sob a perspectiva de Foucault, como elementos de poder utilizados pelo governo para promover a adequação dos sujeitos ao modelo proposto. $O$ autor apresenta uma breve discussão sobre dois livros adotados pelo sistema educacional imperial. O primeiro intitulado "Fábulas", de Justiniano José da Rocha; e o segundo com o título "Lições Moraes e Religiosas", de autoria de José Rufino Rodrigues Vasconcelos. Observase, portanto, em ambos a intenção de incutir valores no alunado, através do ensinamento de princípios éticos e morais condizentes com o projeto da emergente nação.

Tal projeto orientou a organização das instituições de ensino sob a égide liberal e democrática do amplo acesso e direito a educação para todos. O que se colocava em prática, entretanto, era a oferta de mínimo letramento para as classes menos abastadas, enquanto o ensino secundário destinava-se apenas aos filhos da elite, com formação humanística e literária para aqueles que iriam ocupar os cargos reservados aos intelectuais. É claro, portanto, o sectarismo e a orientação do ensino para organização de uma sociedade moldada de acordo com os interesses da classe dirigente.

A partir destas observações fica clara a fundamentação dos questionamentos do autor, que apoiado em Foucault, evidencia a preocupação e a necessidade de empreender um efetivo controle sobre as instituições de ensino. A ideia era, portanto, controlar a escola para moldar o corpo social. De tal modo, o Regulamento de 1854 reafirma a hierarquização social, inclusive ao tomar como modelo de ensino secundário o Imperial Colégio Pedro II, frequentado apenas por meninos de boas condições econômicas.

Diante desse quadro de insuficiência, sectarização e desvalorização profissional, Gondra destaca a iniciativa dos professores, que reunidos publicam um conjunto de 4 cartas-manifesto, sendo 3 destinadas ao governo imperial e 1 destinada aos concidadãos. As mesmas foram agrupadas e publicadas pela "Instrucção Pública" em 1871 sob o título de "Manifesto dos Professores Públicos de Instrução Primária da Corte".

O autor enxerga no manifesto uma tentativa dos docentes de se autogerir, apresentando a sociedade suas habilidades, condições e formação. A sua articulação em torno do manifesto, fomentou também a criação de associações e agremiações profissionais, estimulando a própria consciência de classe. Cabe ressaltar o tom de crítica que permeia o texto do manifesto acerca do descaso estatal com relação a educação e a penosa situação material dos professores da época.

O livro "A emergência da escola" de Gondra nos proporciona uma análise do surgimento da escola enquanto instituição formadora por excelência dos cidadãos brasileiros, em um contexto de governo imperial e sob influências do racionalismo, 
positivismo e darwinismo. Ao propor uma leitura das estratégias de governo das aulas, dos professores e das massas, o autor rompe com uma compreensão determinista e verticalizada das ações estatais, abrindo espaço para as múltiplas forças que se expressam no campo de formação das identidades e das práticas cotidianas.

Assim, o processo de organização da escola não está fora do mundo cultural, social e das disputas políticas. O seu projeto expressa os interesses de uma determinada classe. A escola passa a ser um elemento para o alcance da civilidade e do progresso, mas também serve ao controle e à hierarquização social, contribuindo com e mesmo produzindo o acirramento das desigualdades sociais. A emergência da escola é, portando, para Gondra, um processo dinâmico e de várias facetas, em que a busca por poder, controle e legitimidade passam obrigatoriamente pela sala de aula. 